\title{
Quantification of Iodine Leakage on Dual-Energy CT as a Marker of Blood-Brain Barrier Permeability in Traumatic Hemorrhagic Contusions: Prediction of Surgical Intervention for Intracranial Pressure Management
}

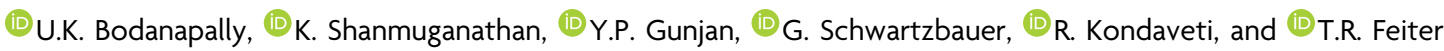

\begin{abstract}
BACKGROUND AND PURPOSE: Hemorrhagic contusions are associated with iodine leakage. We aimed to identify quantitative iodine-based dual-energy CT variables that correlate with the type of intracranial pressure management.

MATERIALS AND METHODS: Consecutive patients with contusions from May 2016 through January 2017 were retrospectively analyzed. Radiologists, blinded to the outcomes, evaluated CT variables from unenhanced admission and short-term follow-up head dualenergy CT scans obtained after contrast-enhanced whole-body CT. Treatment intensity of intracranial pressure was broadly divided into 2 groups: those managed medically and those managed surgically. Univariable analysis followed by logistic regression was used to develop a prediction model.

RESULTS: The study included 65 patients (50 men; median age, 48 years; $Q_{1}$ to $Q_{3}, 25-65.5$ years). Twenty-one patients were managed surgically (14 by CSF drainage, 7 by craniectomy). lodine-based variables that correlated with surgical management were higher iodine concentration, pseudohematoma volume, iodine quantity in pseudohematoma, and iodine quantity in contusions. The regression model developed after inclusion of clinical variables identified 3 predictor variables: postresuscitation Glasgow Coma Scale (adjusted $\mathrm{OR}=0.55 ; 95 \% \mathrm{Cl}, 0.38-0.79 ; P=.001$ ), age (adjusted $\mathrm{OR}=0.9 ; 95 \% \mathrm{Cl}, 0.85-0.97 ; P=.003$ ), and pseudohematoma volume (adjusted $\mathrm{OR}=2.05 ; 95 \% \mathrm{Cl}, 1.1-3.77 ; P=.02$ ), which yielded an area under the curve of 0.96 in predicting surgical intracranial pressure management. The 2 predictors for craniectomy were age (adjusted $\mathrm{OR}=0.89 ; 95 \% \mathrm{Cl}, 0.81-0.99 ; P=.03$ ) and pseudohematoma volume (adjusted $\mathrm{OR}=1.23 ; 95 \% \mathrm{Cl}, 1.03-1.45 ; P=.02$ ), which yielded an area under the curve of 0.89 .
\end{abstract}

CONCLUSIONS: Quantitative iodine-based parameters derived from follow-up dual-energy CT may predict the intensity of intracranial pressure management in patients with hemorrhagic contusions.

ABBREVIATIONS: $A O R=$ adjusted OR; DECT = dual-energy CT; HPC = hemorrhagic progression of contusion; ICP $=$ intracranial pressure; P-GCS = postresuscitation Glasgow Coma Scale; SECT = single-energy CT; TBI = traumatic brain injury; $\mathrm{WBCT}=$ whole-body $\mathrm{CT}$

O ne of the most severe pathoanatomic types of traumatic brain injury (TBI) is hemorrhagic contusion, usually complicated by secondary injury, resulting in cerebral edema leading

Received June 26, 2019; accepted after revision September 30.

From the Departments of Diagnostic Radiology and Nuclear Medicine (U.K.B., K.S., T.R.F.), Neurology (Y.P.G.), and Neurosurgery (G.S.), R Adams Cowley Shock Trauma Center, University of Maryland School of Medicine, Baltimore, Maryland; and Kasturba Medical College (R.K.), Mangaluru, India.

Portions of this work previously presented in abstract form at: Annual Meeting of the Radiological Society of North America, November 25-29, 2018; Chicago, Illinois.

Please address correspondence to Uttam K. Bodanapally, MD, 22 S. Greene Street Department of Radiology and Nuclear Medicine, University of Maryland Medical Center, Baltimore, MD 21201; e-mail: ubodanapally@umm.edu

Indicates article with supplemental on-line table.

Indicates article with supplemental on-line photo.

http://dx.doi.org/10.3174/ajnr.A6316 to increased intracranial pressure (ICP). ${ }^{1-3}$ Vasogenic edema caused by BBB disruption in contusions is an important contributing factor for ICP elevation. ${ }^{4}$ An uncontrolled increase in ICP is a poor prognostic factor in closed-head injuries. ${ }^{5-7} \mathrm{An}$ optimal approach to managing patients with TBI is to anticipate the onset of increased ICP, appropriately monitor it, and manage it when there are clinical manifestations of an impending increase in ICP. ${ }^{8}$ Level II evidence supports ICP monitoring in patients with severe head trauma (Glasgow Coma Scale, <9) and abnormal head CT findings. ${ }^{9}$ However, there are no guidelines for patients with mild and moderate TBI with abnormal CT findings. Symptoms of increased ICP in awake patients may be vague and nonspecific, such as confusion, headache, and drowsiness. ${ }^{6} \mathrm{CT}$ is the primary investigation in such patients because clinically nonobvious abnormalities of cerebral mass effect are manifested as midline shift, effacement of sulci, and compression of basal 
cisterns and ventricles, which are evaluated by the Marshall CT score; however, there are no definitive CT features that determine increased ICP or identify patients who are at increased risk of subsequent ICP elevation. ${ }^{6,10}$ Hence, determination of imaging predictors of the intensity of ICP management would help identify patients at risk of increased ICP and those likely to fail medical management, helping clinicians initiate early monitoring and treatment to limit secondary injury.

There are reports of $\mathrm{CT}$ identification of contrast leakage caused by BBB disruption in cerebral contusions that depend on qualitative assessment of iodine leakage following CTA of the brain. ${ }^{11-14}$ These studies performed on single-energy CT (SECT) showed a correlation between iodine leakage and hemorrhagic progression of contusions (HPC). ${ }^{11-14}$ Although CTA for evaluating TBI is not an accepted standard of care, contrast-enhanced whole-body CT (WBCT) is widely used in the work-up of patients with polytrauma. ${ }^{15}$ The contrast bolus administered during the admission WBCT leaks into and is retained in the epicenter and penumbra of hemorrhagic contusion due to capillary fragmentation and BBB disruption. ${ }^{2}$ Dual-energy CT (DECT) has proved helpful in differentiating and quantifying the iodine leakage from hemorrhages in cerebral infarctions, subdural spaces, and spontaneous hemorrhages. ${ }^{2,16,17}$

Using both unenhanced admission and short-term follow-up head DECTs obtained after WBCT, we aimed to identify imaging variables and clinical parameters that correlate with surgical intervention for ICP management.

\section{MATERIALS AND METHODS \\ Study Design}

This retrospective cohort study was Health Insurance Portability and Accountability Act-compliant, and permission was obtained from University of Maryland School of Medicine review board. Informed consent was waived. Consecutive patients referred to a Level I trauma center from May 2016 through January 2017 were eligible. The inclusion criteria were the following: 1) a history of blunt trauma with acquisition of head CT as a part of WBCT performed on either a DECT or SECT scanner within 6 hours after traumatic impact, with a confirmed diagnosis of hemorrhagic contusions; 2) acquisition of follow-up head DECT within 10 hours of admission CT, to evaluate the progression of TBI; and 3) patients 18 years of age and older. The exclusion criteria were the following conditions: 1) decompressive craniectomy or CSF drainage was initiated before the follow-up CT; 2) nonfocal extraparenchymal hematomas extended over $>1$ lobe, with a width of $>2 \mathrm{~mm}$, and all holohemispheric subdural hematomas, irrespective of the width, to select pure hemorrhagic contusions; and 3) punctate or petechial hemorrhages $(<10 \mathrm{~mm}$ in diameter) in subcortical white matter concomitant with diffuse axonal injury. At the study institution, most patients with blunt trauma are evaluated with admission WBCT. Patients with traumatic lesions on initial CT, patients with persistent altered mental status without traumatic lesions, patients for whom CT fails to explain neurologic status, and patients on anticoagulation without traumatic lesions tend to be evaluated by 6- to 8-hour follow-up head CT. We selected only patients with hemorrhagic contusions as a predominant injury type to limit the confounding effects of noncontusional lesions on ICP.

\section{Study Population}

A search of the radiology information system from the designated time period yielded 219 patients with a follow-up study performed on a DECT scanner within 10 hours of WBCT. A radiologist (reviewer 1, U.K.B.) with 10 years of experience reviewed the initial and follow-up studies to select all the patients with pure hemorrhagic contusions $(n=65)$. They constituted the study group.

Clinical information regarding the mechanism of injury, time from traumatic impact to WBCT, time to follow-up DECT, postresuscitation Glasgow Coma Scale (P-GCS) score, admission blood pressure, blood coagulation parameters, ICP monitoring, opening pressure, hyperosmolar therapy, CSF drainage, and decompressive craniectomy was obtained from the electronic medical records. In intubated patients, a verbal score for P-GCS was derived. ${ }^{18}$

\section{Imaging}

Admission WBCT examinations were performed on a DECT (Somatom Force; Siemens, Erlangen, Germany) or 64-channel SECT (Brilliance 64-channel; Philips Healthcare, Best, the Netherlands). WBCT involves a noncontrast head CT followed by contrast-enhanced CT of the neck, chest, abdomen, and pelvis. The studies were performed after injection of $100 \mathrm{~mL}$ of iodinated contrast media (iohexol, Omnipaque 350; GE Healthcare, Piscataway, New Jersey).

DECT head images were obtained with the $\mathrm{x}$-ray tubes at $80 \mathrm{kV}$ and $\mathrm{Sn} 150 \mathrm{kV}(150 \mathrm{kV}+$ Tin filter). Scan parameters were as follows: rotation time, 0.5 seconds; pitch, 0.55 . The reference milliampere-second was 273 for the Sn $150 \mathrm{kV}$ and 410 for the $80-\mathrm{kV}$ tube. Original dual-energy datasets were reconstructed with an increment of $1 \mathrm{~mm}$ and a section thickness of $1 \mathrm{~mm}$. Automatic reconstruction of $120-\mathrm{kV}$ equivalent mixed DECT images at 5-mm section thickness and 5-mm intervals using an adaptive iterative reconstruction algorithm (ADMIRE; Siemens) with a strength value of 3 was performed and sent to the PACS at the time of study.

\section{Image Analysis of DECT and Definitions}

DECT data from follow-up head CTs were processed to derive 190-keV image sets at 5-mm section thickness and 5-mm intervals on a workstation (syngo.via, Version VB10B; Siemens) and sent to the PACS for the study purpose. A total of 3 image sets were used for volume measurements in each patient: $120-\mathrm{kV}$ DECT or SECT images acquired with $120 \mathrm{kV}$ (peak) (from the admission study) and $120-\mathrm{kV}$ and 190-keV image sets (from the follow-up study). Reviewer 1 annotated all the hemorrhagic contusions that were meant for volume measurements, and admission CT images were evaluated for Marshall CT scores. Volumes were measured using semiautomated 3D segmentation on a thin-client server (Intellispace Portal; Philips Healthcare). Measurements were randomly performed with regard to patient order and the order of the image sets to avoid potential preconceived bias. 
Table 1: Unadjusted associations among predictor variables, surgical management of intracranial pressure, and decompressive craniectomy

\begin{tabular}{|c|c|c|c|c|}
\hline Variables & $\begin{array}{c}\text { Unadjusted Odds } \\
\text { Ratios }(95 \% \mathrm{Cl}) \\
\text { (Surgical Management) }\end{array}$ & $P$ Value & $\begin{array}{l}\text { Unadjusted Odds } \\
\text { Ratios (95\% CI) } \\
\text { (Craniectomy) }\end{array}$ & $P$ Value \\
\hline Age (yr) & $0.96(0.93-0.98)$ & $.004^{\mathrm{a}}$ & $0.94(0.88-0.99)$ & $.04^{\mathrm{a}}$ \\
\hline Sex, men vs women & $0.94(0.27-3.2)$ & $.92^{\mathrm{b}}$ & $0.35(0.07-1.77)$ & $.34^{\mathrm{c}}$ \\
\hline P-GCS & $0.63(0.5,0.8)$ & $<.001^{\mathrm{a}}$ & $0.78(0.6-1)$ & .05 \\
\hline Motor score & $0.43(0.25-0.76)$ & $.003^{a}$ & $0.7(0.44-1.14)$ & .15 \\
\hline Systolic BP (mm Hg) & 0.99 (0.97-1) & .15 & $1.01(0.98,1.04)$ & .46 \\
\hline Diastolic BP (mm Hg) & $0.99(0.97-1.03)$ & .84 & $1(0.96-1.05)$ & .72 \\
\hline PT (seconds) & $0.98(0.84-1.14)$ & .78 & $0.93(0.67-1.3)$ & .64 \\
\hline aPTT (seconds) & $1.03(0.92-1.15)$ & .57 & $1(0.85-1.18)$ & .93 \\
\hline Fibrinogen (mg/dL) & $0.98(0.97-0.99)$ & $.002^{\mathrm{a}}$ & 0.99 (0.98-1) & .06 \\
\hline Platelets $\left(10^{3} / \mu \mathrm{L}\right)$ & 1 (0.99-1.01) & .81 & $1(0.99-1.01)$ & .4 \\
\hline \multicolumn{5}{|l|}{ Marshall CT score } \\
\hline DI II & 1 & & $3.46(0.55-21.9)$ & $.2^{\mathrm{c}}$ \\
\hline DI III and IV & $4.27(0.9-20)$ & $.06^{\mathrm{c}}$ & & \\
\hline Hemorrhagic progression & $1.12(0.35-3.54)$ & $.85^{\mathrm{b}}$ & $2.84(0.32-25.4)$ & $.31^{\mathrm{c}}$ \\
\hline Fraction of hemorrhagic progression & $1.02(0.96-1.11)$ & .49 & $1(0.91-1.1)$ & .88 \\
\hline lodine concentration (mg/mL) & $44(3.03-641)$ & $.005^{\mathrm{a}}$ & $16(0.58-442)$ & .1 \\
\hline Hematoma volume on admission $\mathrm{CT}\left(\mathrm{cm}^{3}\right)$ & $1.05(0.97-1.13)$ & .21 & $1.04(0.95-1.14)$ & .4 \\
\hline Hematoma volume on follow-up CT $\left(\mathrm{cm}^{3}\right)$ & $1.06(1-1.12)$ & $.04^{\mathrm{a}}$ & $1.04(0.99-1.1)$ & .1 \\
\hline Total pseudohematoma from all contusions $\left(\mathrm{cm}^{3}\right)$ & $1.32(1.06-1.64)$ & $.01^{\mathrm{a}}$ & $1.1(0.99-1.23)$ & .06 \\
\hline Fractional pseudohematoma to true hematoma & $2.66(0.6-11.8)$ & .19 & $2.43(0.3-18.9)$ & .39 \\
\hline lodine quantity in all pseudohematomas (mg) & $1.48(1.04-2.11)$ & $.03^{\mathrm{a}}$ & $1.04(0.96-1.13)$ & .3 \\
\hline lodine quantity in all contusions (mg) & $1.1(1.01-1.21)$ & $.02^{\mathrm{a}}$ & $1.03(0.98-1.08)$ & .15 \\
\hline
\end{tabular}

Note-BP indicates blood pressure; DI, diffuse injury; PT, prothrombin time; aPTT, activated partial thromboplastin time.

${ }^{a}$ Significant.

${ }^{\mathrm{b}}$ Pearson.

${ }^{c}$ Fisher exact test.

For measuring the iodine concentration in the contusion, DECT data from follow-up head CT studies were used with the modified Brain Hemorrhage application on the postprocessing workstation (syngo.via). ${ }^{2}$ In patients with $>1$ follow-up head CT, measurements were also obtained from the second follow-up study to facilitate the calculation of the fractional rate of iodine washout from the contusions. Average iodine concentration was measured by drawing an ROI around each contusion. For every contusion, 3 ROIs were drawn, each in axial, coronal, and sagittal sections at the level of the maximum diameter. The average of the 3 ROIs was obtained. The mean values obtained by the 2 reviewers (reviewer 1 and reviewer 2 [K.S.] with 25 years of experience) were used for analysis.

\section{Variable Construction}

We analyzed the relationship of 20 study variables derived from clinical, laboratory, and CT data (Table 1 and On-line Table).

\section{Study Term Definitions}

Initial and Follow-Up Hematoma Volumes. Initial hematoma volume was measured on $120 \mathrm{kV}$ or SECT images and labeled as (A) (Fig 1A); volume measurements on follow-up DECT were obtained on both $120-\mathrm{kV}$ images (B) (Fig 1B) and on 190-keV (Fig 1C) images (C).

Pseudohematoma and Fraction of Pseudohematoma. Pseudohematoma is defined as enhancing penumbra caused by an iodine leak on follow-up $120-\mathrm{kV}$ images. ${ }^{2}$ The attenuation contribution of iodine tends to be negligible at $190 \mathrm{keV}$, therefore demonstrating attenuation only from the hematoma, allowing measurement of true hematoma volume. ${ }^{2}$ Hence, with the availability of hematoma volume on $120 \mathrm{kV}$ - (true hematoma + enhancing penumbra) and true hematoma volume on $190-\mathrm{keV}$ images, the pseudohematoma volume can be calculated as the following: Pseudohematoma Volume $=(B-C)$, where $B$ is the volume on $120-\mathrm{kV}$ and $C$ is volume on $190-\mathrm{keV}$ images. Fraction of pseudohematoma $=(B-C) / C$.

lodine Concentration. The average iodine concentration (milligram/milliliter) was measured on iodine maps (Fig $1 D$ ). The normalized iodine concentration was not analyzed because the quantification was performed hours after contrast administration with complete washout from blood vessels.

lodine Quantity in Pseudohematoma and Contusion. Iodine quantity in pseudohematoma $=([B-C] \times$ Iodine Concentration). Iodine quantity in total contusion $=(B \times$ Iodine Concentration).

Hemorrhagic Progression of Contusion and Fraction of Hemorrhagic Progression of Contusion. Hemorrhagic progression of contusion is designated as enlargement of the existing hemorrhagic contusion ( $30 \%$ volume increase) or the appearance of a new lesion. ${ }^{2}$ Fraction of $\mathrm{HPC}=(C-A) /(A)$.

Fractional Rate of lodine Washout. The fractional rate of iodine washout from the contusions was calculated using the following formula:

$$
W R_{\mathrm{F}}=I_{\mathrm{c}(1)}-I_{\mathrm{c}(2)} / I_{\mathrm{c}(1)} \times 100 / \Delta \mathrm{T},
$$

Where $W R_{\mathrm{F}}$ represents the fractional rate of washout, $I_{\mathrm{C}(1)}$ and $I_{\mathrm{C}(2)}$ are the iodine concentrations in the first and second follow- 

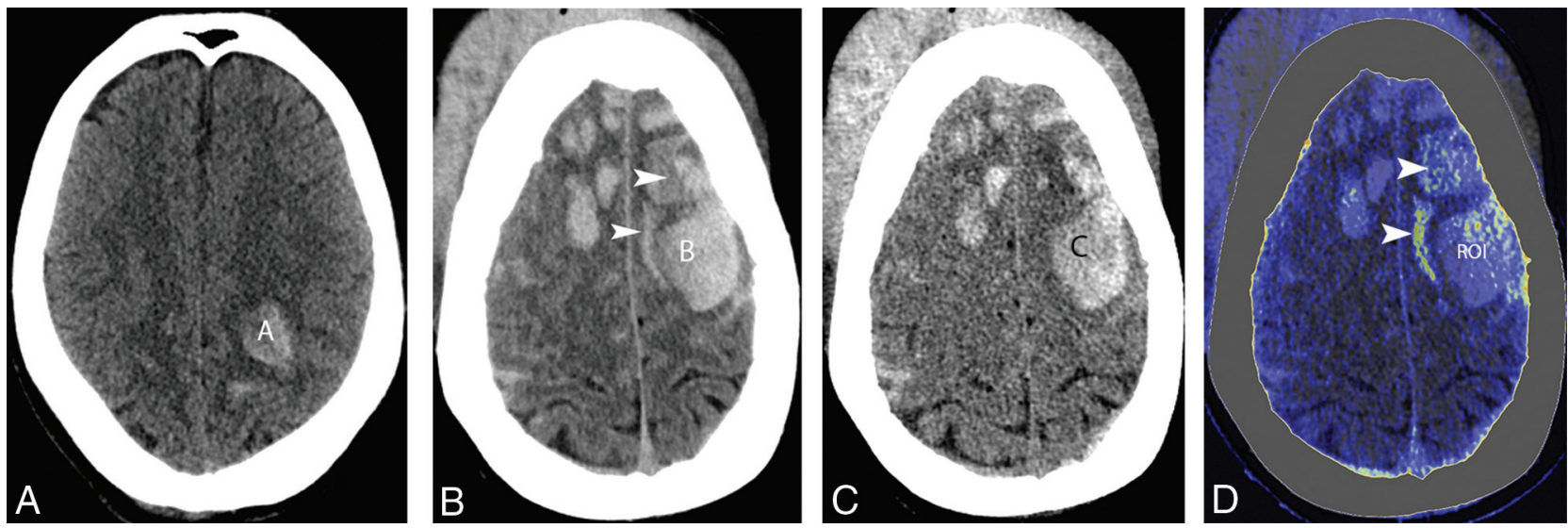

FIG. A 65-year-old man with traumatic brain injury sustained after a motor vehicle collision. A, Admission 120-kV image shows a hemorrhagic contusion in the left frontoparietal lobe and measured volume $\left(A=11.4 \mathrm{~cm}^{3}\right)$. B. Follow-up axial 120-kV image shows hemorrhagic progression of contusions with increased volume of the existing hematoma $\left(B=38.3 \mathrm{~cm}^{3}\right)$ with multiple new hemorrhagic contusions. The image also shows areas of contrast leakage (arrowheads). C, Virtual high-monochromatic image (190 kV) shows smaller hemorrhagic contusion volume $\left(C=27.9 \mathrm{~cm}^{3}\right)$, compared with $120-\mathrm{kV}$ images due to a negligible attenuation contribution from leaked iodinated contrast. $D$, lodine overlay image shows contrast staining of the penumbra and parapenumbra of hemorrhagic contusions (arrowheads). An ROI is drawn around the largest hematoma to measure the iodine concentration $(0.8 \mathrm{mg} / \mathrm{mL})$.

up studies, respectively, and $\Delta \mathrm{T}$ represents the duration (hours) between the 2 studies.

\section{Outcome Assessment: Therapeutic Intensity of ICP Management}

Increased ICP is managed by a stepwise increase in the intensity of treatment starting with medical management and escalating to surgical intervention of CSF drainage in refractory cases and craniectomy as a last surgical option for severe refractory ICP elevation. ${ }^{6,8,19}$ For this study, treatment levels were broadly divided into 2 groups: those managed medically and those managed surgically by CSF drainage or craniectomy. Medical management at the study institution includes head elevation, adequate oxygenation, fluid resuscitation, sedation, muscle relaxation, and mild hyperventilation, with or without hyperosmolar therapy.

\section{Statistical Analysis}

Statistical analysis was performed using commercially available statistical software (JMP 12 software; SAS Institute, Cary, North Carolina). Data from continuous variables are summarized as mean \pm SD for normally distributed variables and median (first quartile $\left[\mathrm{Q}_{1}\right]$, third quartile $\left[\mathrm{Q}_{3}\right]$ ) for non-normally distributed variables. Categoric variables are summarized as counts and percentages. The association between each predictor of interest and outcomes was examined using the $\chi^{2}$ test or Fisher exact test for categoric predictors and simple logistic regression for continuous predictors. The effect of each predictor of interest on surgical ICP management and craniectomy without adjusting for other predictors and the unadjusted odds ratio and corresponding 95\% confidence intervals were calculated. For both categoric outcomes, predictors with $P<.1$ on unadjusted analysis were incorporated into the logistic regression analysis. The independent predictors for each outcome were developed using the backwardelimination method. The final predictors for each outcome of interest were selected on the basis of the Akaike information criterion. A $P$ value of .05 indicated significance. For the prediction model for each outcome, receiver operating characteristic analysis was performed to assess the overall predictive ability of the model using the area under the receiver operating characteristic curve.

\section{RESULTS}

Baseline clinical characteristics of the cohort $(n=65)$ are shown in the On-line Table. Of the 65 patients in the study cohort, 44 patients were medically managed, including hyperosmolar therapy in 20 patients. There were 21 patients managed surgically (14 by CSF drainage, 7 by craniectomy); all 21 patients had a trial of hyperosmolar therapy before escalating treatment to an operation. The median time from impact to WBCT was 1 hour 30 minutes $\left(\mathrm{Q}_{1}=1.12\right.$ hours, $\mathrm{Q}_{3}=2$ hours), and the median time to follow-up head DECT was 6 hours $\left(\mathrm{Q}_{1}=4\right.$ hours, $\mathrm{Q}_{3}=7.25$ hours). All contusions showed iodine leakage, with a concentration ranging from 0.1 to $1 \mathrm{mg} / \mathrm{mL}$ (median $=0.43 \mathrm{mg} / \mathrm{mL}, \mathrm{Q}_{1}$, $\mathrm{Q}_{3}=0.23-0.53 \mathrm{mg} / \mathrm{mL}$ ). The correlation between the 2 reviewers' measurements of iodine concentration was very strong $(r=0.923)$. The correlation between predictors is shown in the On-line Figure. In patients with multiple contusions $(n=28)$, there was a strong correlation between the iodine concentration in the largest contusion with the mean concentration in smaller contusions $(r=0.94)$. The median fraction of pseudohematoma to the true hematoma was 0.31 or $31 \%(\mathrm{Q} 1=$ $0.11, \mathrm{Q} 3=0.58$ ).

\section{Surgical Management}

Twenty-one patients were managed surgically (14 by CSF drainage, 7 by craniectomy). DECT variables that correlated with surgical ICP management were higher iodine concentration ( $\mathrm{OR}=44 ; 95 \% \mathrm{CI}, 3.03-641 ; P=.005)$, pseudohematoma volume (OR $=1.32 ; 95 \% \mathrm{CI}, 1.06-1.64 ; P=.01)$, iodine quantity in 
Table 2: Adjusted associations among predictor variables, surgical management of intracranial pressure, and decompressive craniectomy

\begin{tabular}{|c|c|c|c|c|}
\hline Variables & $\begin{array}{c}\text { Adjusted Odds Ratios } \\
\text { (95\% CI) (Surgical } \\
\text { Management) }\end{array}$ & $\begin{array}{c}P \\
\text { Value }\end{array}$ & $\begin{array}{l}\text { Adjusted Odds } \\
\text { Ratios }(95 \% \mathrm{CI}) \\
\text { (Craniectomy) } \\
\end{array}$ & $\begin{array}{c}P \\
\text { Value }\end{array}$ \\
\hline Age (yr) & $0.9(0.85-0.97)$ & $.003^{\mathrm{a}}$ & $0.89(0.81-0.99)$ & $.03^{\mathrm{a}}$ \\
\hline $\begin{array}{l}\text { Total pseudohematoma } \\
\text { from all contusions }\left(\mathrm{cm}^{3}\right)\end{array}$ & 2.05 (1.11-3.77) & $.02^{\mathrm{a}}$ & $1.23(1.03-1.45)^{\prime}$ & $.02^{\mathrm{a}}$ \\
\hline P-GCS & $0.55(0.38-0.79)$ & $.001^{\mathrm{a}}$ & & \\
\hline
\end{tabular}

${ }^{a}$ Significant.

pseudohematoma $(\mathrm{OR}=1.48 ; 95 \% \mathrm{CI}, 1.04-2.11 ; P=.03)$, and iodine quantity in contusion $(\mathrm{OR}=1.1 ; 95 \% \mathrm{CI}, 1.01-1.21$; $P=.02)$. The conventional CT variable that correlated was hematoma volume on follow-up CT (OR $=1.06$; 95\% CI, 1-1.12; $P=.04)$. Clinical variables that correlated were younger age $(\mathrm{OR}=0.96 ; 95 \% \mathrm{CI}, 0.93-0.98 ; P=.004)$, lower P-GCS $(\mathrm{OR}=$ 0.63 ; 95\% CI, 0.5-0.8; $P<.001)$, lower motor score $(\mathrm{OR}=0.43$; 95\% CI, 0.25-0.76; $P=.003$ ), and lower fibrinogen (OR $=0.98$; 95\% CI, 0.97-0.99; $P=.002$ ). Complete details are provided in Table 1. The regression model developed after combining the clinical variables and CT variables identified 3 predictors with significance in the determination of surgical ICP management (Table 2): P-GCS (adjusted odds ratio [AOR] = 0.55; 95\% CI, 0.38-0.79; $P=.001$ ), age (AOR = 0.9; 95\% CI, 0.85$0.97 ; P=.003$ ), and pseudohematoma volume ( $\mathrm{AOR}=2.05$; 95\% CI, 1.1-3.77; $P=.02)$. The 3 variables resulted in an $R^{2}$ of $0.6(P<.001)$ (Table 2). On average, a 1-unit (cubic centimeter) increase in pseudohematoma volume increased the odds of surgical ICP management by $105 \%$. Receiver operating characteristic analysis of the regression model in predicting surgical ICP management yielded an area under the curve of 0.96 .

\section{Decompressive Craniectomy}

The variables that correlated with decompressive craniectomy on univariable analysis were young age and lower P-GCS. Complete details are provided in Table 1 . The regression model developed after inclusion of variables with $P<.1$ on unadjusted analysis identified 2 predictors with significance: age $(\mathrm{AOR}=0.89 ; 95 \%$ CI, 0.81-0.99; $P=.03$ ) and pseudohematoma volume $(\mathrm{AOR}=$ 1.23; 95\% CI, 1.03-1.45; $P=.02)$, with an $R^{2}$ of $0.32(P<.001)$ (Table 2). On average, a 1-unit (cubic centimeter) increase in pseudohematoma volume increased the odds of craniectomy by $23 \%(\mathrm{AOR}=1.23 ; 95 \% \mathrm{CI}, 1.03-1.45 ; P=.02)$. Receiver operating characteristic analysis of the regression model in predicting craniectomy yielded an area under the curve of 0.89 .

Iodine quantity either in pseudohematoma or the contusion showed a strong linear correlation (0.95) with pseudohematoma volume; hence, these factors can be interchangeable in the regression model.

\section{lodine Washout Rates}

A second follow-up DECT was available in 37 patients. In these patients, there was a slow and gradual decrease in the iodine concentrations with a median of $2.22 \%\left(Q_{1}=0, Q_{3}=9.6\right)$. There was no correlation between the iodine concentration and washout rates (Spearman $\rho=0.25, P=.13$ ). Serial iodine concentrations measured in patients with $>2$ followup studies $(n=22)$ demonstrated that the complete washout of iodine was seen as soon as 56 hours and contrast was retained in the contusion for as long as 147 hours after injection. Analysis performed by adjusting the iodine concentration to the median time to follow-up CT of 6 hours showed identical predictors for surgical ICP management and decompressive craniectomy.

\section{DISCUSSION}

Our cohort included predominantly a specific type of pathoanatomic injury (ie, contusions) with the most commonly used CT classification scheme (the Marshall CT score) as well as contusion volumes on admission and follow-up CT studies and compared them with the quantitative iodine-based DECT variables. We excluded large extraparenchymal hematomas because those pathoanatomic injury types do not share a common pathophysiologic mechanism of primary and secondary damage that influences the ICP. ${ }^{20}$ The major findings from our study are the following: In traumatic cerebral contusions with a short-term follow-up head DECT after admission WBCT, quantitative iodine-based DECT variables correlated with surgical ICP management; pseudohematoma volume derived from DECT was the only imaging predictor of both surgical ICP management and craniectomy; and the clinical variables P-GCS and age were additional predictors of surgical ICP management, while age was the only clinical predictor of craniectomy.

Studies have shown a correlation between the presence of iodine leak with HPC and craniectomies after TBI. ${ }^{11-14}$ In contrast to previous studies, our results did not show a correlation between leaked iodine concentration and craniectomy, but they correlated with surgical ICP management. This difference might be due to qualitative assessment of images on SECT and by using various threshold levels of Hounsfield units to confirm leaks. However, we identified pseudohematoma volume derived from DECT as the best imaging predictor of surgical ICP management and craniectomy. Pseudohematoma that constitutes approximately 30\% (Q1 = 10, Q3 = 57) (On-line Table) of the median value of the contusion represents the volume of enhancing penumbra. The predictive ability of pseudohematoma is because it represents the volume of parenchyma that shows BBB disruption, hence a higher volume correlating with the magnitude of ICP elevation according to Monro-Kellie hypothesis. ${ }^{8}$ Animal models have demonstrated the concept of progressive microvascular failure associated with contusions, in which the peak kinetic energy delivered to the epicenter resulted in immediate capillary fragmentation and hemorrhage. However, the energy deposited in the penumbra is not enough to fracture capillaries but is enough to activate mechanosensitive molecular processes. This upregulates sulfonylurea receptor 1 , implicated in delayed microvascular dysfunction resulting in a permeable endothelium. ${ }^{2,21}$ Iodine leaks through the same permeable endothelium manifest as enhancing penumbra. SECT fails to assess the volume of enhancing penumbra, while DECT enables the measurement of 
the volume, thus proving to be superior to the commonly used Marshall CT score in predicting elevated ICP requiring surgical management.

Age and P-GCS were clinical predictors of surgical ICP management and age for craniectomy. The predictive ability of younger age might be due to the lack of involutional changes of cerebral volume loss; thus, younger patients are prone to ICP elevation by milder forms of cerebral edema compared with older patients. Use of the ratio of parenchymal volume to CSF volume as a measure of the degree of brain involution as a predictor variable may yield more accurate results. However, age may be used as an effective surrogate for the magnitude of brain atrophy until a robust validated automated volume-quantification software becomes widely available. Finally, a low P-GCS that represents more severe TBI as a predictor of surgical ICP may be related to the high mechanical force at impact that propagates through a large volume of parenchyma, causing diffuse edema contributing to ICP, as opposed to more localized injury.

The current TBI classification relies on the primary presentation (Glascow Coma Scale) without considering the second phase that includes the role of BBB permeability. ${ }^{22,23}$ Establishing a routine, inexpensive, and minimally invasive technique to measure the degree of BBB disruption might improve the TBI classification and also would streamline patients for ICP monitoring and the treatment approach for increased ICP. ${ }^{24} \mathrm{CT}$ perfusion and contrast-enhanced MR imaging are the currently available imaging techniques for detection of BBB breakdown that rely on detection of the retained contrast agent in the interstitium. However, these techniques are not widely accepted for patients with TBI due to additional cost, time, and potential for additional radiation (class IIb recommendations). ${ }^{25}$ Animal studies have shown that extravasation through the BBB occurs immediately after shock loading, reaches maximum intensity by 4 hours, and gradually resolves in 4 days after impact. ${ }^{26-28} \mathrm{CT}$ contrast (iohexol, with a low molecular weight $[<2 \mathrm{kDa}]$ ) can be used for measuring this transient increase in permeability. The ability to quantify iodine using increasingly available DECT technology in major academic and Level I trauma centers provides a good alternate imaging technique to assess $\mathrm{BBB}$ disruption.

\section{Strengths and Limitations}

The strength of our study derives from its unique ability to assess BBB disruption and the prediction of surgical ICP management in a subset of patients with TBI with hemorrhagic contusions using the current standard of care admission WBCT and follow-up DECT data, without any additional penalty of cost, time, and radiation. Limitations include its retrospective, single-center design, which introduces selection and institutional bias. Additionally, the cohort comprised hemorrhagic contusions as the major form of injury. Therefore, these data cannot be generalized to all patients with TBI, especially those with major extraparenchymal bleeds. Finally, this study does not evaluate the optimum temporal window to obtain the follow-up studies (though most follow-up scans [75\%] were performed within 7 hours 15 minutes).

\section{CONCLUSIONS}

Quantitative iodine-based parameters derived from follow-up DECT after admission contrast-enhanced WBCT can be used to predict surgical ICP management and craniectomy in patients with hemorrhagic contusions. The identified predictors can help discriminate patients who would fail medical management and can help clinicians initiate early ICP monitoring and treatment.

Disclosures: Uttam K. Bodanapally_UNRELATED: Grants/Grants Pending: Siemens, Comments: artificial intelligence for detecting traumatic brain injuries*; Payment for Lectures Including Service on Speakers Bureaus: Siemens, Comments: symposium; Travel/Accommodations/Meeting Expenses Unrelated to Activities Listed: Siemens, Comments: travel to the symposium. *Money paid to the institution.

\section{ACKNOWLEDGMENT}

The authors thank Brigitte Pocta for editing the manuscript.

\section{REFERENCES}

1. Stiell IG, Clement CM, Grimshaw JM, et al. A prospective clusterrandomized trial to implement the Canadian CT Head Rule in emergency departments. CMAJ 2010;182:1527-32 CrossRef Medline

2. Bodanapally UK, Shanmuganathan K, Issa G, et al. Dual-energy CT in hemorrhagic progression of cerebral contusion: overestimation of hematoma volumes on standard $120-\mathrm{kV}$ images and rectification with virtual high-energy monochromatic images after contrast-enhanced whole-body imaging. AJNR Am J Neuroradiol 2018; 39:658-62 CrossRef Medline

3. Smith M. Monitoring intracranial pressure in traumatic brain injury. Anesth Analg 2008;106:240-48 CrossRef Medline

4. Unterberg AW, Stover J, Kress B, et al. Edema and brain trauma. Neuroscience 2004;129:1019-27 CrossRef

5. Marshall LF, Smith RW, Shapiro HM. The outcome with aggressive treatment in severe head injuries, Part II: acute and chronic barbiturate administration in the management of head injury. $J$ Neurosurg 1979;50:26-30 CrossRef Medline

6. Li LM, Timofeev I, Czosnyka M, et al. The surgical approach to the management of increased intracranial pressure after traumatic brain injury. Anesth Analg 2010;111:736-48 CrossRef Medline

7. Juul N, Morris GF, Marshall SB, et al; Executive Committee of the International Selfotel Trial. Intracranial hypertension and cerebral perfusion pressure: influence on neurological deterioration and outcome in severe head injury. J Neurosurg 2000;92:1-6 CrossRef Medline

8. Jantzen J. Prevention and treatment of intracranial hypertension. Best Pract Res Clin Anaesthesiol 2007;21:517-38 CrossRef Medline

9. Bratton SL, Chestnut RM, Ghajar J, et al; Brain Trauma Foundation; American Association of Neurological Surgeons; Congress of Neurological Surgeons; Joint Section on Neurotrauma and Critical Care, AANS/CNS. Guidelines for the management of severe traumatic brain injury, VI: indications for intracranial pressure monitoring. J Neurotrauma 2007;24(Suppl 1):S37-44 CrossRef Medline

10. Miller MT, Pasquale M, Kurek S, et al. Initial head computed tomographic scan characteristics have a linear relationship with initial intracranial pressure after trauma. J Trauma 2004;56:967-73 CrossRef Medline

11. Rosa M Jr, da Rocha AJ, Maia AC Jr, et al. Contusion contrast extravasation depicted on multidetector computed tomography angiography predicts growth and mortality in traumatic brain contusion. J Neurotrauma 2016;33:1015-22 CrossRef Medline

12. Letourneau-Guillon L, Huynh T, Jakobovic R, et al. Traumatic intracranial hematomas: prognostic value of contrast extravasation. AJNR Am J Neuroradiol 2013;34:773-79 CrossRef Medline

13. Huang AP, Lee CW, Hsieh HJ, et al. Early parenchymal contrast extravasation predicts subsequent hemorrhage progression, clinical 
deterioration, and need for surgery in patients with traumatic cerebral contusion. J Trauma 2011;71:1593-99 CrossRef Medline

14. Orito K, Hirohata M, Nakamura Y, et al. Predictive value of leakage signs for pure brain contusional hematoma expansion. $J$ Neurotrauma 2018;35:760-66 CrossRef Medline

15. Huber-Wagner S, Lefering R, Qvick LM, et al; Working Group on Polytrauma of the German Trauma Society. Effect of whole-body CT during trauma resuscitation on survival: a retrospective, multicentre study. Lancet 2009;373:1455-61 CrossRef Medline

16. Bodanapally UK, Dreizin D, Issa G, et al. Dual-energy CT in enhancing subdural effusions that masquerade as subdural hematomas: diagnosis with virtual high-monochromatic $(190-\mathrm{keV})$ images. AJNR Am J Neuroradiol 2017;38:1946-52 CrossRef Medline

17. Bonatti M, Lombardo F, Zamboni GA, et al. Iodine extravasation quantification on dual-energy $\mathrm{CT}$ of the brain performed after mechanical thrombectomy for acute ischemic stroke can predict hemorrhagic complications. AJNR Am J Neuroradiol 2018;39:441-47 CrossRef Medline

18. Meredith W, Rutledge R, Fakhry SM, et al. The conundrum of the Glasgow Coma Scale in intubated patients: a linear regression prediction of the Glasgow verbal score from the Glasgow eye and motor scores. J Trauma 1998;44:839-45 CrossRef Medline

19. Rangel-Castilla L, Rangel-Castillo L, Gopinath S, et al. Management of intracranial hypertension. Neurol Clin 2008;26:521-41 CrossRef Medline

20. Saatman KE, Duhaime AC, Bullock R, et al. Classification of traumatic brain injury for targeted therapies. J Neurotrauma 2008; 25:719-38 CrossRef Medline
21. Simard JM, Chen M, Tarasov KV, et al. Newly expressed SUR1-regulated NC(Ca-ATP) channel mediates cerebral edema after ischemic stroke. Nat Med 2006;12:433-40 CrossRef Medline

22. Jacobs B, Beems T, van der Vliet TM, et al. Computed tomography and outcome in moderate and severe traumatic brain injury: hematoma volume and midline shift revisited. J Neurotrauma 2011; 28:203-15 CrossRef Medline

23. Bodanapally UK, Sours C, Zhuo J, et al. Imaging of traumatic brain injury. Radiology Clin North Am 2015;53:695-715 CrossRef Medline

24. Shlosberg D, Benifla M, Kaufer D, et al. Blood-brain barrier breakdown as a therapeutic target in traumatic brain injury. Nat Rev Neurol 2010;6:393 CrossRef Medline

25. Wintermark M, Sanelli PC, Anzai Y, et al. Imaging evidence and recommendations for traumatic brain injury: advanced neuro- and neurovascular imaging techniques. AJNR Am J Neuroradiol 2015; 36:E1-11 CrossRef Medline

26. Habgood MD, Bye N, Dziegielewska KM, et al. Changes in bloodbrain barrier permeability to large and small molecules following traumatic brain injury in mice. Eur J Neurosci 2007;25:231-38 CrossRef Medline

27. Bharadwaj VN, Lifshitz J, Adelson PD, et al. Temporal assessment of nanoparticle accumulation after experimental brain injury: effect of particle size. Sci Rep 2016;6:29988 CrossRef Medline

28. Kuriakose M, Rao KV, Younger D, et al. Temporal and spatial effects of blast overpressure on blood-brain barrier permeability in traumatic brain injury. Sci Rep 2018;8:8681 CrossRef Medline 